\title{
O TRABALHO DE EQUIPE NO PROGRAMA DE SAÚDE DA FAMÍLIA: REFLEXÕES A PARTIR DE CONCEITOS DO PROCESSO GRUPAL E DE GRUPOS OPERATIVOS
}

\author{
Cinira Magali Fortuna ${ }^{1}$ \\ Silvana Martins Mishima ${ }^{2}$ \\ Silvia Matumoto ${ }^{1}$ \\ Maria José Bistafa Pereira ${ }^{2}$
}

Fortuna CM, Mishima SM, Matumoto S, Pereira MJB. O trabalho de equipe no programa de saúde da família: reflexões a partir de conceitos do processo grupal e de grupos operativos. Rev Latino-am Enfermagem 2005 março-abril; 13(2):262-8.

O presente estudo é uma revisão teórica sobre o trabalho de equipe no Programa de Saúde da Família. Definimos trabalho de equipe em saúde como uma rede de relações entre pessoas, relações de poderes, saberes, afetos, e desejos, onde é possível identificar os processos grupais. Abordamos conceitos da Escola Argentina de Grupos Operativos, os quais podem auxiliar os trabalhadores de saúde a se treinarem a operar como equipe. Nas equipes, temos tarefas visíveis (faladas) e invisíveis (não ditas), que se modificam e que precisam ser combinadas e conhecidas. A comunicação, a aprendizagem, o sentimento de pertencer, o "clima", a pertinência entre as ações realizadas e a finalidade da equipe, as relações de poder, podem ajudar a equipe a se conhecer, analisar-se e ir se construindo como equipe. Terminamos assinalando que a supervisão externa pode auxiliar a equipe a produzir-se em equipe operativa, na direção de seu projeto de cuidar da vida.

DESCRITORES: saúde da família; equipe de assistência ao paciente; estrutura de grupo; relações interprofissionais; trabalho; instituições de saúde; enfermagem

\section{TEAM WORK IN A FAMILY HEALTH CARE PROGRAM: THE TEAM PROCESS CONCEPT AND OPERATIONAL TEAMS}

This work is a theoretical revision of team work in a family Health Care Program. We define team work in the health care field as a relationship network among people, power, knowledge, affection, and wishes, when there is a possibility of identifying group processes. We deal with concepts of Operational Group from the Argentinean School, which might help health professionals to get training in team work. We have visible (spoken) and invisible (unspoken) tasks within teams, which are modified and need to be combined and known. Communication, learning, the feeling of belonging, the atmosphere, the actions' pertinence for the team's purpose and power relations may help the team to get to know and analyze each other and to build a team. External supervision may help the team to turn itself into an operational team, working towards a life care project.

DESCRIPTORS: family health; patient care team; group structure; interprofessional relations; work; health facilities; nursing

\section{EL TRABAJO DEL EQUIPO EN EL PROGRAMA DE SALUD DE LA FAMILIA: REFLEXIÓN A PARTIR DE CONCEPTOS DEL PROCESO GRUPAL Y DE GRUPOS OPERATIVOS}

El presente estudio es una revisión teórica sobre el trabajo de equipo en el Programa de Salud de la familia. Definimos trabajo de equipo como una red de relaciones entre personas, relaciones de poderes, saberes, afectos y deseos donde es posible identificar los procesos grupales. Abordamos conceptos de la escuela Argentina de Grupos Operativos que pueden auxiliar a los trabajadores de salud a entrenarse para operar como equipo. En los equipos tenemos tareas visibles (habladas) e invisibles (no dichas), que se cambian y que necesitan ser combinadas y conocidas. La comunicación, el aprendizaje, el sentimiento de pertenecer, el "clima", la pertinencia entre las acciones realizadas y la finalidad del equipo y las relaciones de poder pueden ayudar al equipo a conocerse, analizarse e ir construyéndose como equipo. Terminamos señalando que la supervisión externa puede auxiliar el equipo a producirse en equipo operativo en la dirección de su proyecto de cuidar de la vida.

DESCRIPTORES: salud de la familia; grupo de atención al paciente; estructura de grupo; relaciones interprofesionales; trabajo; instituciones de salud; enfermería

\footnotetext{
${ }^{1}$ Enfermeira da Secretaria Municipal da Saúde de Ribeirão Preto, Doutoranda na Escola de Enfermagem de Ribeirão Preto, da Universidade de São Paulo, e-mail: cinirafortuna@yahoo.com.br, e-mail: smatumoto@uol.com.br; ${ }^{2}$ Professor Doutor da Escola de Enfermagem de Ribeirão Preto, da Universidade de São Paulo, Centro Colaborador da OMS para o desenvolvimento da pesquisa em enfermagem, e-mail: smishima@eerp.usp.br, e-mail: zezebis@eerp.usp.br
} 


\section{APRESENTAÇÃO}

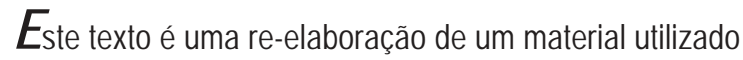
para a discussão do tema Trabalho de Equipe no Programa de Saúde da Família (PSF), tendo, inicialmente, a finalidade de nortear uma exposição dialogada nos treinamentos introdutórios realizados pelo Pólo Norte/Oeste Paulista de Formação Acadêmica e Capacitação de Recursos Humanos para Saúde da Família.

Foi construído com base no referencial teórico de Grupo Operativo da Escola Argentina de Grupos ${ }^{(1)}$, na constituição da rede de relações, no interior de uma equipe de trabalhadores da atenção básica em saúde ${ }^{(2)}$ e reflexões elaboradas a partir do contato com as equipes de trabalhadores de saúde, em diversas situações e cursos.

Trata-se de uma revisão teórica sobre a prática do trabalho de equipe em saúde, com exemplificações generalizadas apreendidas pelo contato com diversas equipes e trabalhadores, em linguagem de fácil compreensão e identificação, especialmente para os trabalhadores que estão se aproximando dessa temática.

Pretendemos que este texto favoreça a leitura conjunta por todos os trabalhadores que integram as equipes de Saúde da Família, com o objetivo de contribuir com alguns elementos para reflexão sobre a formação, construção e revisão do trabalho em equipe.

\section{INTRODUÇÃO}

O Programa de Saúde da Família é uma proposta do Ministério da Saúde para implantação e implementação do Sistema Único de Saúde e vem sendo apresentado institucionalmente como alternativa para mudança de modelo assistencial ${ }^{(3)}$. Nele, o trabalho de equipe está proposto como uma das prerrogativas estratégicas para a mudança do atual modelo de assistência em saúde ${ }^{(4)}$.

$O$ atual modelo assistencial é caracterizado pela fragmentação da assistência, pela consideração do corpo biológico como objeto de trabalho, pela centralidade das ações nos atos médicos e medicalizadores.

A proposta do Programa de Saúde da Família é a de uma equipe composta minimamente por um médico generalista, 4 a 6 agentes comunitários de saúde, trabalhadores de saúde bucal (um conjunto para cada duas equipes), dois auxiliares de enfermagem e um enfermeiro, cuidando de 800 a 1000 famílias adscritas a uma área de abrangência $^{(3)}$.

Cabe a essa equipe desenvolver ações de promoção à saúde, prevenção de doenças e prestação de cuidados específicos à família, aspectos estes, de algum modo, já conhecidos e praticados pelos trabalhadores da atenção básica. Cabe, ainda, à equipe de saúde da família a elaboração do diagnóstico da área de atuação, articulação de ações intersetoriais; promoção da mobilização e organização dos moradores e 0 desenvolvimento de cidadania, aspectos estes ainda não incorporados à prática cotidiana.

Assim, coloca-se para os trabalhadores o desafio do trabalho em equipe para fazeres que eles desconhecem e precisam desbravar, construir, inventar, o que pode complexificar ainda mais as relações entre os trabalhadores do Programa de Saúde da Família.

Existem diferentes formas de se considerar trabalho em equipe e também diferentes finalidades para sua proposição. De um modo geral, as publicações sobre 0 trabalho em equipe na saúde referem-se ao conjunto de trabalhadores de um mesmo estabelecimento, os quais são referidos como equipe apenas por trabalharem juntos. Mas há também referências a essa modalidade de trabalho como possibilidade de realização do atendimento integral, e da articulação dos saberes e disciplinas necessários para o atendimento em saúde ${ }^{(2,5)}$.

Nessa segunda vertente, não consideramos o trabalho de equipe relacionado a uma categoria profissional como a da enfermagem ${ }^{(6)}$ por exemplo. Consideramos o trabalho de equipe como possibilidade de "recomposição" do trabalho em saúde numa outra direção, a da interdisciplinaridade.

Pretendemos superar essa forma já bem conhecida, em que o usuário chega com uma queixa ao serviço, passa por diferentes trabalhadores, cada um faz uma parte do atendimento até chegar ao médico. Assim, a queixa é decodificada e transformada numa conduta normalmente medicalizante, ou seja: são prescritos remédios e atitudes individuais descontextualizadas que nem sempre são seguidas e nem sempre impactam positivamente na saúde daquela pessoa ou daquelas pessoas que vivem e moram na área onde a Unidade de Saúde se propõe atuar.

Na saúde, também temos uma complexidade para o trabalho em equipe, pois ele implica e envolve necessariamente uma produção. O que é mesmo que se produz nos serviços de saúde? Produzimos algo que não é material, não tem uma forma concreta e interfere diretamente na maneira de viver das pessoas. Esse bem não material tem significados diferentes para diferentes pessoas, em diferentes etapas de suas vidas, em diferentes culturas e momentos da história da humanidade.

O trabalho em saúde produz um bem não material que não se armazena, não é possível deixar saúde guardada nas prateleiras, não é mesmo? E o trabalho em saúde também produz os trabalhadores e a equipe.

Quantas vezes escutamos e falamos que trabalhar em um dado lugar mudou nosso jeito de ser? Por exemplo: a agente comunitária que, antes de ser agente, era muito tímida para falar em público e agora faz palestras, vai à tribuna da Câmara Municipal, faz reunião de quarteirão. Ela se modificou no trabalho, nas relações de trabalho.

Mas, então, o que é trabalhar em equipe, em saúde da 
família? Só o fato de existir um conjunto de trabalhadores contratados para o PSF e atuando numa mesma área, aparentemente com um objetivo comum, temos o desenvolvimento do trabalho em equipe? Não necessariamente. Ali ocorre trabalho, acontecem relações que, às vezes, são difíceis de se compreender, e que podem deixar os trabalhadores e usuários muito longe daquilo que pretendem realizar no PSF, como, por exemplo, mudar o jeito de se trabalhar em saúde.

Assim, consideramos a equipe como um processo de relações a serem permanentemente "olhadas". Por quem? Pelos próprios trabalhadores e com múltiplas possibilidades de significados. Podemos dizer que o trabalho em equipe vai se constituindo, gestando-se no seu fazer de todo dia, e precisa ser analisado, pois passa por movimentos de dificuldades, de paralisação, de satisfação, enfim, é também um processo de idas e vindas em diversas direções.

Consideramos o trabalho de Equipe em Saúde como uma rede de relações entre pessoas, rede de relações de poderes, saberes, afetos, interesses e desejos, onde é possível identificar processos grupais. Trabalhar em equipe eqüivale a se relacionar ${ }^{(2)}$.

Notadamente, esses processos parecem intensificados pelo próprio objeto de trabalho da equipe, que, no caso, é a família e compõe uma outra grupalidade.

Para analisar essas relações, podemos nos valer de referenciais teóricos sobre os processos grupais. Nesse texto, vamos utilizar alguns conceitos referentes aos grupos operativos que podemos identificar nas equipes, com a intenção de auxiliá-las no processo de compreensão e criação de sua práxis, ações transformadoras desde sua análise, recriando, assim, o próprio trabalho.

\section{AS EQUIPES E OS GRUPOS}

Consideramos a possibilidade de que as equipes se treinem como tais, por meio do uso da técnica dos grupos operativos ${ }^{(7)}$ desenvolvidos por diversos autores da EscolaArgentina de Grupos ${ }^{(1,8-}$ 9). Os grupos também têm sido utilizados para formação de trabalhadores de saúde, como no Projeto Larga Escala, cuja base pedagógica é a reflexão para a modificação da realidade ${ }^{(10)}$.

O grupo operativo é definido como um conjunto de pessoas com um objetivo comum, que opera e se estrutura à medida que se relaciona. Grande parte do trabalho do grupo operativo consiste no treinamento para operar como equipe. A técnica pode não dar conta do que ocorre nas relações da equipe, e, por isso, é necessário lançar mão de um ECRO que permita observar e analisar fenômenos que se dão nos grupos, nas instituições e em suas relações mútuas. Se não é possível a coincidência conceitual e processual entre a equipe e grupo operativo, é possível tomar os elementos da técnica como base conceitual que permita desenvolvimentos e modificações pertinentes ${ }^{(11)}$.
ECRO, para a escola pichoniana ${ }^{(1)}$, é o Esquema Conceitual Referencial e Operativo do grupo. Constitui-se de um conjunto de noções, regras, acordos, conceitos gerais, que permite ao grupo aproximar-se de um objeto, de algo que está explorando e conhecendo, uma espécie de baliza de referência conceitual e operativa.

Consideramos que, nas equipes, acontecem processos grupais que precisam ser conhecidos pelos próprios integrantes, para que, juntos, possam criar significados, problematizando suas ações e atualizando as suas relações entre si, com aqueles a que atendem, esclarecendo e revendo o que tomam por problema de saúde e por ação.

Essa seria a possibilidade de criação do referido ECRO que, de modo simplificado, seria a construção, pela equipe do entendimento, de suas relações, das suas ações e das demandas que se apresentam no serviço, trazidas pelos usuários. Essas demandas geram angústias nos trabalhadores ${ }^{(11)}$, pois ultrapassam a dimensão para a qual fomos preparados, a dimensão do cuidado biológico, do corpo, das partes. São, muitas vezes, demandas que solicitam apoio, soluções e escuta diferentes, de outra referência, de outro ECRO.

Falar de equipes e grupos não equivale a dizer que esses dois termos são sinônimos, mas que, por meio da compreensão dos processos grupais presentes nas relações cotidianas das equipes, se pode construir a equipe, sua capacidade de gerar críticas e significados distintos daqueles a que já nos acostumamos e que apenas reproduzem o jeito conhecido de trabalhar.

\section{ALGUNS OUTROS CONCEITOS SOBRE GRUPOS OPERATIVOS A SEREM ANALISADOS PELA EQUIPE DO PSF: A TAREFA EXPLÍCITA, IMPLÍCITA, OS PROJETOS E OBJETIVOS}

Em nosso trabalho em saúde, também no PSF, nós nos relacionamos para desenvolver uma tarefa, temos um fazer conjunto que precisa ser maior do que a soma das parcelas do trabalho de cada um dessa equipe.

Alguém que vai a casa, alguém que medica, alguém que prescreve, alguém que aplica a vacina, alguém que ensina e orienta, etc.

Cada integrante da equipe possui um saber, uma história de vida diferente, uma formação específica e, com isso, a tendência é a de não considerarmos tais diferenças e trabalharmos como numa fábrica, onde cada um faz um pedaço: um aperta parafuso, outro pinta, outro embala, etc.

Como articular essas características de cada um para desenvolvermos um trabalho coletivo, um trabalho em equipe? 
Principalmente, um trabalho voltado para produzir saúde de um modo diferente, priorizando o acolhimento, a humanização, o desenvolvimento da responsabilização e da cidadania?

O trabalho em saúde vai ser mesmo dividido porque cada um tem algo de específico a realizar, tem um conjunto de conhecimento que permite um certo fazer, por exemplo: o agente não vai prescrever um medicamento, nem o médico vai aos domicílios cotidianamente, para realizar e atualizar o cadastro das famílias. Então, como dividir as ações sem perder de vista a finalidade de trabalho e a especificidade de cada trabalhador?

Possivelmente conversando e elaborando planos de atendimento em conjunto para cada família, definindo mais claramente o fazer de cada um em relação ao caso. Nessa hora em que os trabalhadores se reúnem para conversar, podemos visualizar, com mais intensidade, os processos grupais.

Sentar junto para conversar parece tão fácil, mas, muitas vezes, não é, pois, nesses momentos, deparamos com as contradições, com as diferenças, com as expectativas que temos uns dos outros e que não são claramente faladas.

Muitos autores já escreveram sobre a importância das reuniões para as equipes ${ }^{(2,12)}$, e alguns chamam a atenção para o fato de que esse espaço pode servir para que nada se modifique, para que tudo permaneça da mesma forma. Atrasos freqüentes, o entrar e sair a toda hora, a dificuldade de encerrar, o término que se dá pelo esvaziamento, a dificuldade de concluir com propostas, são alguns indicativos de que a reunião não está sendo operativa, nem contribuindo para mudar o jeito de trabalhar; ao contrário, está a serviço da reprodução do velho jeito de atender.

Vejamos, agora, a questão dos objetivos das equipes e das tarefas explícita e implícita.

As equipes e os grupos, quando se reúnem, têm objetivos e tarefas a desempenhar. Esses objetivos e as tarefas podem estar ou não claras aos integrantes de um grupo de trabalhadores.

Esse é, então, um ponto importante para o trabalho em equipe. Todos sabem qual é o objetivo, e quais as tarefas do conjunto de trabalhadores?

Aonde a Equipe do PSF quer chegar com seu trabalho? (qual o seu projeto?)

Fizemos o cadastramento, levantamos, em conjunto com os moradores, as prioridades, vamos, assim, estabelecer uma série de tarefas para alcançar um objetivo comum.

Exemplificando: o primeiro diagnóstico mostrou-nos que um dos problemas a serem enfrentados é o da gravidez em adolescentes.

Queremos chegar à redução de gravidez indesejada na adolescência (nosso objetivo); para isso, uma série de tarefas terão que ser realizadas: iniciando-se pela compreensão ampliada do problema, poderemos desenvolver grupos com adolescentes, articular- nos com professores da área de abrangência, realizar oficinas de teatro, entre outras ações.

Com esse exemplo, podemos perceber que tanto os objetivos mudam como as tarefas, e que é fácil continuarmos realizando uma ação, perdendo de vista seu porquê e para quê. É de se esperar que o objetivo seja ou não alcançado e que as tarefas sejam avaliadas e recriadas por todos os envolvidos.

Imaginemos uma equipe de Saúde da Família que continua fazendo os grupos de adolescentes, anos após anos, sem parar para analisar se está ou não atingindo o objetivo proposto. Essa tarefa passa a ser apenas uma escala a mais a ser cumprida.

Acontece que, nos grupos e nas equipes que começam a trabalhar juntos, existem os objetivos ou tarefas visíveis (explícitas) e tarefas invisíveis ou implícitas.

O objetivo visível de uma equipe de Saúde da família pode ser 0 de atender, numa área de abrangência, a um número $\mathrm{x}$ de famílias. Disso todos os membros dessa equipe podem ter conhecimento.

Mas 0 atender pode se fazer de muitas maneiras: pode se fazer com 0 atendimento pontual de uma queixa (dor de cabeça = analgésico), pode se fazer encaminhando as pessoas para outros serviços, pode se fazer conhecendo essas famílias, identificando, com elas, suas necessidades e como o modo de viver afeta sua saúde.

Mas a equipe e seus vários integrantes podem fazer isso por diferentes motivos:

- porque precisa do salário, porque acredita que está ajudando a população, porque entende que no PSF poderá atender melhor, porque, se não fizer tal atividade, o Município não receberá a verba do Ministério da Saúde, porque foi o emprego encontrado nesse momento, etc.

Estamos dizendo que, numa equipe, também estão colocados objetivos individuais que também podem ser diferentes e desconhecidos pela equipe.

Tanto os objetivos individuais como aqueles que são do grupo vão se modificando e, por isso, as equipes precisam estar conversando a respeito deles.

Consideramos esse como um outro fator importante para 0 desenvolvimento das equipes.

Até aqui, dissemos que os grupos e as equipes precisam ter um algo comum a desenvolver, objetivos e tarefas. Dissemos que esse algo comum vai se dar numa dada direção (modelo de assistência e projeto). Vamos, então, buscar entender qual tarefa invisível está colocada para as equipes. Essa tarefa invisível tem a ver com os afetos e vínculos estabelecidos entre os trabalhadores.

Quando nos encontramos com outras pessoas, quer para atendê-las, quer para trabalhar com elas, estamos, na verdade, nos re-encontrando: encontrando de novo.

Vêm à nossa mente, num plano nem sempre consciente, 
pessoas com as quais já nos relacionamos nessa nossa singular história de vida

Alguns desses encontros fizeram-se em situações agradáveis e gratificantes, outros não.

Trazemos conosco, assim, nossas experiências anteriores, de outras equipes com as quais já trabalhamos, de outras famílias, das nossas próprias. Tem um que não gosto porque tem o jeito da fulana, outro que gosto mais por me lembrar siclano, etc.

Quando duas pessoas se encontram, temos, então, pelo menos três: eu, o outro, e a imagem que fazemos um do outro. Para o trabalho de equipe, faz-se necessário a atualização, dentro de nós, desse outro e da imagem que dele fazemos. Nossa tendência é a de cristalizar essas imagens e assim vamos nos relacionando de uma forma superficial, rotulando nosso próximo: Na equipe, o Dr é assim...A enfermeira é assim.... O agente de saúde, sempre foi assim mesmo ...

Consideramos que as pessoas não são assim de um jeito eterno e fixo, elas estão dessa forma, nesse momento, podendo estar de outro jeito, conforme a situação.

São essas pessoas que, com o seu fazer, seu modo de agir e pensar que vão construindo o jeito de trabalhar em saúde.

O modo de trabalhar e a forma como o trabalho está organizado influencia as relações da equipe de trabalho. O contrário também é verdadeiro: as relações influenciam o jeito de trabalhar.

Numa equipe em que as pessoas chegam cedo à unidade $e$ vão cada um para uma sala, um fazendo a pré-consulta, outro fazendo a pós-consulta, outro fazendo a consulta, outro medicando, etc, temos a possibilidade de encontrar relações de pouco vínculo ou com os vínculos desatualizados, podendo haver muita insatisfação e talvez desentendimentos freqüentes que nem sempre são resolvidos e explicitados.

Os trabalhadores são também responsáveis diretos por essa forma de trabalho. Somos "feitos" pelo nosso trabalho e nele nos "fazemos". Fazemos o trabalho em saúde, nos fazemos nele.

Essas questões fazem com que venham a se estabelecer tarefas implícitas, invisíveis: estamos aqui para atender o mínimo possível, ou para não atender, estamos aqui para realizar um trabalho com qualidade.

Muitas vezes, o discurso da equipe está bastante homogêneo, todos falam da mesma tarefa, mas, no ato, no fazer de todo dia, cada um dirige seus esforços numa direção, ou em direções contrárias àquelas discursadas.

Podemos assim criar uma série de normas e rotinas voltadas para o objetivo do não atendimento, (ou do rápido atendimento), que parece ser comum nas equipes de saúde e, ao mesmo tempo, vamos, também, dirigindo nossas ações e rotinas para 0 atendimento integral, para a defesa da vida. Essa é uma das opções em permanente disputa no interior das equipes.

Parece que as equipes criam situações de "defesa", principalmente naqueles serviços onde não se tem clareza do objetivo, das tarefas e finalidades do trabalho, vindo a predominar os projetos individuais: trabalhar sem se envolver muito, ganhar um salário no fim do mês, manter outro emprego, etc.

\section{OS VETORES DOS GRUPOS E ANÁLISE DAS EQUIPES}

Os grupos podem passar por determinados períodos e por determinados momentos e movimentos que podem ser analisados por meio dos vetores ${ }^{(1)}$ abaixo descritos. Esses vetores podem nortear as equipes na análise de sua dinâmica, para se constituir como equipe e alcançar seus objetivos.

\section{AFILIAÇÃo}

Refere-se, principalmente, aos primeiros contatos entre os trabalhadores quando se conheceram e souberam que iriam trabalhar juntos. É importante assinalar que fazemos escolhas e, no caso do PSF, os trabalhadores fizeram a opção de se afiliarem a uma dada equipe.

\section{PERTENÇA}

À medida em que os trabalhadores vão convivendo uns com os outros, vão desenvolvendo o sentimento de que fazem parte da equipe, de que pertencem a ela.

O sentimento de pertença não se dá por si só, ele vai sendo constituído. Você já se pegou perguntando-se: será que vou me adaptar a esse novo trabalho? Será que essas pessoas vão aceitar meu jeito de fazer as coisas? Antes era difícil, mas, agora, sou da equipe do PSF...

\section{COMUNICAÇÃO}

Esse é um indicador importante dos vários momentos possíveis de se viver num grupo e numa equipe.

A comunicação pode estar se produzindo em meio a ruídos, gerando mal-entendidos e situações paralisantes. Também pode ser um instrumento para crescimento e troca.

A comunicação envolve ainda mais que um emissor, uma mensagem e um receptor, envolve esse caminho todo, o contexto, os gestos, os lugares de quem fala (posição na equipe),etc.

Podemos dizer que, nos grupos (também nas equipes), muitas coisas podem estar sendo faladas e compartilhadas sem estarem sendo ditas explicitamente. Essas coisas ditas assim, de modo implícito, precisam ser esclarecidas, colocadas na mesa, checadas. 


\section{APRENDIZAGEM}

A aprendizagem caminha como que em um trilho de trem, isto é, ao lado da comunicação. Aprender está sendo tomado, aqui, como algo que ultrapassa a transferência de saber de uma pessoa a outra. Estamos falando de um aprender com o outro e não do outro.

Num grupo, numa equipe em que a comunicação está se fazendo com ruídos, com interferências, a aprendizagem fica paralisada, pois as trocas estão comprometidas.

\section{COOPERAÇÃO}

A cooperação diz respeito à articulação dos integrantes da equipe, de seus saberes, e de seus fazeres, para a execução da tarefa a que esse grupo se propõe.

O par "oposto" da cooperação éa competição. Nos momentos de muita competição, a cooperação tende a ser quase ausente e viceversa.

\section{PERTINÊNCIA}

Tem a ver com o compromisso da equipe, com as tarefas a que se propôs.

Uma equipe do PSF, que estabelece como tarefa tomar por objeto a família em seu contexto, e passa a atender somente indivíduos na perspectiva de medicar suas queixas, está sem pertinência, com uma de suas tarefas explícita.

\section{TELE}

Esse aspecto do grupo diz respeito ao "clima" que sentimos nas reuniões e encontros. O "clima" pode estar tenso, pode estar de satisfação e amabilidade, enfim varia conforme o momento vivido.

"Climas" muito permanentes, que ficam muito tempo da mesma forma, podem indicar conflitos aparentemente ocultos ou paralisações desse grupo.

\section{AS INDIVIDUALIDADES E AS EQUIPES: OS GRUPOS, FASES, MITOS E PODERES}

Todos compartilhamos a idéia, de uma certa forma, de que as equipes e os grupos são espaços onde acontecemos, existimos, criamos e satisfazemos necessidades.
No entanto, quando estamos num grupo, vivemos um conflito, uma dúvida entre ser indivíduo e ser grupo, ou estar indivíduo e estar grupo, fazer ou não parte da equipe.

Existe um medo básico denominado medo do ataque e da perda. Medo do ataque daquilo que já conhecemos, medo da perda da individualidade, e isso gera uma certa ansiedade. Envolve mudanças quem ao mesmo tempo desejamos e tememos. Mudanças requerem novas adaptações, nova aprendizagem.

Numa equipe em constituição e início, devido a esses medos básicos, existe uma certa tendência a se mostrarem as diferenças, 0 tanto que um sabe mais que o outro, o tanto que um "pode" mais que 0 outro.

Não de uma forma linear, e com a disponibilidade de seus integrantes, os grupos vão superando esse primeiro momento de mostrar mais a diferença e passam a desejar uma igualdade. Procuram as semelhanças, cedem no que pensam, temem mostrar-se diferentes.

Na medida em que os integrantes da equipe se vinculam, se conhecem, se aceitam, vão compreendendo suas diferenças e semelhanças de um modo mais "inteiro". Percebem-se tendo dificuldades e facilidades em diferentes intensidades e as manifestam em distintos momentos $^{(1)}$.

Os integrantes da equipe vão, assim, rodiziando papéis, trocando saberes, construindo-se como equipe. Vão vivenciando papéis análogos aos vividos por integrantes de um grupo. Dentre os diferentes papéis possíveis, vamos nos ater aos de liderança. Basicamente dizem respeito a lideranças para a mudança, para a superação dos conflitos, ou para a elaboração das tarefas visíveis e invisíveis.

Podem surgir, ainda, lideranças para a resistência à mudança, quando algum ou alguns integrantes ajudam o grupo a não realizar sua tarefa. Sabotam, seduzem, obstaculizam. Esses são papéis complementares no grupo, o grupo permite a situação. Precisamos identificar quais lideranças podem estar surgindo na equipe e em que direção se faz o liderar; se para a tarefa ou para a não-tarefa.

Nos grupos, o rodízio de liderança e de papéis é um fator de saúde, quanto maior a possibilidade de que, em diversas situações, líderes diferentes assumam os papéis, ainda que de resistência à mudança, maiores as chances de descristalizações e de não rotulações dos integrantes.

Ainda é importante pensar se estão surgindo subgrupos, divisões e como a equipe enfrenta suas dificuldades.

Falar de trabalho em equipe não é falar de algo harmonioso. É falar de pessoas em relação, que terão momentos de conflitos e que esses não são "negativos", "ruins", ou algo a ser evitado, mas são inerentes as relações, são possibilidades de crescimento, se forem trabalhados.

Não poderíamos deixar de abordar, também, as relações de poder que vão se tecendo no interior das equipes. Quando falamos de 
poder, estamos nos referindo não aos governos, prefeitos e chefias, mas à polarização que se estabelece entre as pessoas, dividindo-as entre as que "podem" mais e as que podem menos, fazendo uma hierarquia nas relações. Algumas profissões foram adquirindo poder durante a história, é o caso da categoria profissional médica.

Essa configuração de poder tende a perpetuar e a reproduzirse na divisão técnica e social do trabalho. Já nos referimos a essa divisão em que cada um faz uma parte do trabalho (divisão técnica), com um valor social diferente (divisão social do trabalho). Fica estabelecido, de uma certa forma acordado, que quem "sabe mais", pode mais e manda mais nos que "sabem menos" e, por isso, devem obedecer.

O profissional médico vem detendo poder dentro da equipe, e isso pode dificultar sua inserção na equipe, numa posição diferente que não na vertical, mandando. Também, historicamente, a enfermeira disputa poder com o médico, disputa o controle dos outros trabalhadores, e, na equipe de saúde da família, essas disputas históricas estão presentes e precisam ser esclarecidas, conhecidas, reveladas. É comum ir se fazendo toda a rede de relações sobre essa trama de poder, na perspectiva de mantê-la ou de refutá-la.

São comuns as discordâncias colocadas na direção de se manter poder ou de se rebelar a esses poderes.

Na equipe, as relações de poder são complementares, não temos os ditadores sem os submissos.

Além disso, todos os trabalhadores têm um certo poder e autogoverno, fazem o que acham que precisam fazer, independente de suas chefias. Ainda que esses poderes fiquem mais num plano não

\section{REFERÊNCIAS BIBLIOGRÁFICAS}

\section{Pichon-Rivière E. O processo grupal. $3^{\mathrm{a}}$ ed. São Paulo (SP): Martins Fontes; 1982.}

2. Fortuna CM. O trabalho de equipe numa unidade básica de saúde: produzindo e reproduzindo-se em subjetividades. Em busca do desejo, do devir e singularidades. [dissertação]. Ribeirão Preto (SP): Escola de Enfermagem de Ribeirão Preto/USP; 1999.

3. Ministério da Saúde (BR). Secretaria de assistência à Saúde. Coordenação de Saúde da Comunidade. Saúde da Família: uma estratégia para a reorientação do modelo assistencial. $2^{\mathrm{a}}$ ed Brasília (DF): Ministério da Saúde; 1998.

4. Ciampone MHT, Peduzzi M. Trabalho em equipe e trabalho em grupo no Programa de Saúde da Família. Rev Bras Enfermagem 2000 dezembro; 53(especial):143-7.

5. Peduzzi M. Equipe multiprofissional de saúde: a interface entre trabalho e interação. [doutorado]. Campinas (SP): Faculdade de Ciências Médicas/UNICAMP; 1998.

6. Pereira MCA, Favero N. A motivação no trabalho da equipe de enfermagem. Rev Latino-am Enfermagem 2001; 9(4):7-12. visível. Quem desconhece o poder que, muitas vezes, a auxiliar de serviço exerce na equipe, no sentido de determinar, independentemente das normas, o jeito que trabalha, o modo de limpar ou não limpar?

Trabalhar em equipe requer rever poderes, desocultar os poderes, olhar se sua disputa não está incoerente com a direcionalidade do trabalho: no caso do PSF, a democratização e a construção de trabalhadores e usuários cidadãos.

\section{CONCLUSÃO}

A equipe não se faz apenas pela convivência de trabalhadores num mesmo estabelecimento de saúde. Precisa ser construída e entendida como uma estrutura em permanente desestruturação/re-estruturação.

Apostamos na possibilidade de crescimento e construção das equipes se houver disponibilidade para trabalhar seus processos grupais, ou seja, pensar conjuntamente sobre os aspectos abordados: a tarefa, a finalidade do trabalho, a imagem do outro, a forma como tem se dado a comunicação, como está a tele, a aprendizagem, a afiliação, pertença, a pertinência no grupo e a distribuição dos poderes.

Acreditamos que a existência de um supervisor ${ }^{(13)}$ possa ajudar, não estamos falando de chefes ou de gerentes, mas de alguém fora da equipe, capaz de auxiliá-la a conversar, e ir, por si mesma, encontrando suas respostas num movimento que nunca termina, $\mathrm{e}$ acrescenta infindavelmente, tanto para as pessoas individualmente como para a própria equipe.

7. Bleger J. Temas de psicologia entrevista e grupos. São Paulo (SP): Martins Fontes; 1985.

8. Quiroga AP. Enfoques y perspectivas en psicología social. Buenos Aires (AR): Ediciones Cinco; 1994.

9. Saidon O. O grupo operativo de Pichon-Rivière. In: Baremblitt GF, organizador. Grupos: teoria e técnica. Rio de Janeiro (RJ): Graal; 1982. p.169-80.

10. Almeida $A H$, Soares CB. A dimensão política do processo de formação de pessoal auxiliar: a enfermagem rumo ao SUS. Rev Latinoam Enfermagem 2002 setembro/outubro; 10(5):629-36.

11. Martín El. Apuntes para una psicologíasocial de los equipos (de salud mental). In: Bauleo A, Duro JC, Vignale R. La concepción operativa de grupo. Madrid (ES): Associacion Española de Neuropsiquiatria; 1990. p.191-221.

12. Scherer EA, Campos MA. O trabalho de equipe interdisciplinar em saúde mental: uma revisão da literatura. Estudos em Saúde Mental 1987; 264-85.

13. Campos GWS. Um método para análise e co-getão de coletivos: a constituição do sujeito, a produção de valor de uso e a democracia em instituições: o método da roda. São Paulo (SP): Hucitec; 2000. 